\section{Community violence and childhood asthma prevalence in peripheral neighborhoods in Salvador, Bahia State, Brazil}

\author{
Violência comunitária e prevalência de asma em \\ crianças na periferia de Salvador, Bahia, Brasil
}

Guilherme da Costa Alves 1

Darci Neves Santos 1

Caroline Alves Feitosa 1

Mauricio Lima Barreto 1

\section{Introduction}

This study aimed to identify degrees of exposure to community violence reported by parents and guardians of children from four to 12 years of age and the association with childhood asthma symptoms. A cross-sectional study was conducted with 1,232 parents/guardians in 24 peripheral neighborhoods in Salvador, the capital of Bahia State, Brazil. The authors investigated asthma symptoms in children and acts of violence in the community. More than 75\% of parents/guardians had been exposed to community violence in the previous year, with $20 \%$ reporting high levels of exposure. Children that were more exposed to violence showed higher asthma prevalence (28.4\%) as compared to non-exposed children (16.4\%). Children exposed to maximum levels of violence were nearly twice as likely to present asthma symptoms (adjusted OR = 1.94; 95\%CI: 1.12-3.36). The study highlighted the relevance of community violence as a risk factor for asthma and the need for further research to elucidate methodological issues.

Violence; Asthma; Child
Asthma is the most widely prevalent childhood illness 1 , with high mortality rates in various countries 1,2 . It occurs more frequently in poorer areas of large cities, and some studies suggest that lifestyle changes and the characteristics of Western urbanization are responsible for the increase in its incidence 2,3.

In Brazil, population studies have shown a $24.3 \%$ mean prevalence of asthma symptoms, one of the highest rates in the world 4,5. Studies on asthma emphasize the influence of various risk factors including low birth weight, poverty, air pollution, housing conditions, and exposure to smoke and allergens 1,3 .

Many of the factors contributing to asthma symptoms in developed countries appear not to explain a major portion of the prevalence in Latin America 2,3,6. Importantly, while in the developed countries a high proportion of asthma cases is related to allergy, most cases in Latin America and other developing regions are associated with non-allergic or non-atopic mechanisms, suggesting the need to reassess risk factors for asthma in these contexts 3,6. Evidence shows that lifestyle factors such as diet and psychosocial aspects 2,7 can contribute to the high asthma prevalence in Latin America.

Among psychosocial factors, violence has been reported as potentially associated with the occurrence of asthma symptoms 8,9,10,11,12. 
Conceptualized as a complex phenomenon that involves individuals, interpersonal relations, communities, and societies 13 , violence is defined as the intentional use of physical force or power between individuals or groups, resulting in injury, psychological harm, or death 13,14 . Community violence consists of violent acts between individuals that may or may not know each other, but without a family connection. It occurs in communities influenced by factors from the socioeconomic context, generally associated with poverty, death squads, and warring between rival drug gangs 13,15 . Homicides are the extreme manifestation of community violence, with mean rates three times higher than the suicide rates in African and Latin American countries 13. In 2005, Brazil reported 25.8 homicides per 100,000 inhabitants, one of the highest rates in the world 16.

Studies in the United States have shown that children exposed to community violence whether direct victims themselves or members of families that have suffered violence - display higher stress levels and more asthma symptoms $8,9,10,11,12$. The sample used by all these studies consisted of poor populations with heavy exposure to community violence. Several hypotheses have been raised to explain the association between violence and asthma. Findings suggest that families living in more violent communities keep their children longer at home, thus favoring contact with indoor allergens and triggering asthma attacks 10,12. Evidence also shows that stress can directly trigger asthma symptoms $17,18,19$, becoming a mediator between community violence and asthma. It follows logically that violence in communities can aggravate asthma symptoms by reducing access to health services 12 .

Despite the importance and apparent relationship between the two phenomena (both highly frequent in the Latin American context), no studies were identified on the association between asthma and community violence in populations in this region. The current study thus aimed to identify the level of community violence reported by residents of peripheral areas in a city in Northeast Brazil and to examine the influence of level of violence on the occurrence of asthma in children living in these neighborhoods.

\section{Method}

\section{Study design, population, and area}

This was a cross-sectional study conducted in 2006 with 1,445 children ranging from four to 12 years of age, randomly selected from 24 micro- areas located in peripheral neighborhoods in the city of Salvador, Bahia State, Brazil 2. As part of the SCAALA study 2 (Social Change, Allergy and Asthma in Latin America), the questionnaires applied to parents/guardians of children included community violence among the risk factors for asthma and allergy. Our sample excluded 133 participants due to incomplete responses on community violence and 80 due to incongruent responses, leaving 1,232 subjects that comprised the final study sample. There were no differences between the final study sample and the $213 \mathrm{ex}$ cluded respondents in relation to prevalence of asthma symptoms, children's age or gender, or maternal schooling.

\section{Study instruments}

Asthma symptoms were evaluated using the questionnaire from the International Study of Allergy and Asthma in Childhood 5, adapted and standardized for the Brazilian population.

In order to evaluate socio-demographic conditions, we applied questions on maternal schooling and age, children's sex and age, housing conditions like outdoor paving and indoor wall plaster, and family income, in addition to children's body mass index.

\section{Community violence}

A questionnaire containing six items with yes-orno answers was used to evaluate the occurrence of violent acts in the community. Parents/guardians were asked whether they had been direct victims of assault, whether they knew someone who had been assaulted, if they were aware of warring between drug gangs in the neighborhood, whether they knew anyone who had been beaten or injured with a firearm or knife, and whether they knew anyone who had been murdered. All the questions referred to a one-year period prior to the interview. These items were chosen on the basis of international studies investigating community violence and using similar questions 10,20, in addition to three other studies in which community violence was defined as having been a victim or having witnessed a violent act in the community 9,12, as well as school absences due to fear of violence 11 .

\section{Data collection}

Professional psychologists and psychology students previously trained to apply the questionnaires visited the children's homes from January to November 2006 in order to collect psychosocial data. Data on respiratory problems and 
socioeconomic data had been collected previously, from June to October 2005, by another team of trained interviewers. In both data collections, the data were furnished by the child's mother or principal caregiver.

\section{Definition of variables}

\section{- Dependent variable}

Presence of asthma was defined as the occurrence of wheezing in the previous 12 months, associated with the presence of at least one of the following: any lifetime episode of asthma; wheezing during physical exercise; four or more episodes of wheezing in the previous year; or waking at night at least once a week due to wheezing in the previous year. The variable was categorized dichotomously as presence or absence of asthma symptoms.

\section{- Main independent variable}

The "community violence" variable was constructed from five items selected from the original list of six. One of the six items was excluded, since the subject was asked whether she or he had been beaten or injured with a firearm or knife, but the perpetrator was not identified and thus could have been a family member, in which case the act would be classified as domestic rather than community violence. The score for exposure to community violence was structured, assigning 0 to items with negative answers and 1 for positive answers. The sum of the items comprised a score varying from zero exposure (absence of violence) to an exposure of 4 to 5 (maximum exposure to violence), with various intermediate degrees, namely: minimal (level 1), moderate (level 2), and high (level 3). The score's composition in five degrees follows the model adopted in two North American studies 10,20.

The data were entered into Epi Info version 6.0 (Centers for Disease Control and Prevention, Atlanta, USA), and the statistical analyses were performed in Stata version 9.0 (Stata Corp., College Station, USA).

\section{- Covariates}

A literature search identified variables that acted as risk factors for asthma and that were associated with the target exposure, namely community violence. Maternal schooling and age, children's age and sex, income, housing conditions, overweight in the child, and parents' history of asthma are known to be associated with asthma in the child $1,3,6,21,22,23$. In addition, division of the sample by micro-area could influence the manifestation of community violence, a contextual phenomenon associated with poverty that affects micro-areas differently, such that control of the analyses for this indicator is recommended.

\section{Data analysis}

We initially conducted analyses of frequencies and percentages for each item individually, for the score on exposure to community violence, and for the occurrence of asthma symptoms and potential confounders. We then verified the distribution of the community violence score in relation to the prevalence of asthma symptoms.

To estimate the association between community violence and prevalence of symptoms, two strategies were adopted:

- The association between each item individually (direct victim of assault, knowing someone who had been assaulted, knowing someone who had been beaten or injured with a firearm or knife, awareness of gang wars or drug traffic in the neighborhood, and knowing someone who had been murdered) and the occurrence of asthma symptoms.

- The association between each level in the community violence score and the occurrence of asthma symptoms, taking " 0 " exposure as the reference (negative response to all the items).

For both strategies in the definition of exposure to community violence, we estimated the association with asthma symptoms, using contingency tables with estimation of Pearson's $\chi^{2}$ and the $\mathrm{p}$-value. This was followed by logistic regression analysis to estimate the association between each item individually and the presence of asthma, as well as for each level in the community violence score. We estimated the measure of association (odds ratios and respective 95\%CI) through crude modeling and adjustment for potential confounders.

\section{Ethical issues}

The research protocol was submitted to and approved by the Institutional Review Board of the Institute of Collective Health at the Federal University in Bahia (Instituto de Saúde Coletiva, Universidade Federal da Bahia). Informed consent was obtained from the respondents. All the relevant clinical results were sent to the parents / guardians, and whenever necessary specific recommendations were made for clinical treatment cases. Parents/guardians that presented symptoms of severe mental distress or that spontaneously requested psychological support were instructed to seek public mental health services. 


\section{Results}

\section{Characterization of the study population}

Of the 1,232 children from four to 12 years of age, $560(47.7 \%)$ were girls, with a large proportion of children six and seven years old $(35.4 \%)$. The majority of the families (51.1\%) had incomes of one monthly minimum wage or less, $34.3 \%$ had no paving in front of their homes, and approximately $10 \%$ of the houses had no plastering on the indoor walls. Prevalence of asthma symptoms in the sample was $23.1 \%(\mathrm{n}=284)$, and only $13.4 \%$ had a family history of asthma. Based on body mass index, $4 \%$ of the children were undernourished and $14.7 \%$ were overweight. As for schooling, a high percentage of mothers (71.1\%) had less than a complete secondary school education (Table 1).

\section{Characterization of community violence}

Some $17.8 \%$ of the respondents had been victims of assault, $30.2 \%$ knew someone who had been assaulted, $23.7 \%$ knew someone who had either been beaten or injured with a firearm or knife, $46.2 \%$ were aware of gang war or drug traffic in the neighborhood, and $30 \%$ knew someone who had been murdered (Table 1).

In relation to exposure to community violence, $23.2 \%$ of the interviewees had not been exposed to violence in the previous year, while $31.1 \%$ had been exposed to a minimal degree; $25.8 \%$ to a moderate degree; $14.4 \%$ to a high degree; and $5.5 \%$ to a maximum degree of violence (Figure 1 ). Maximum exposure corresponded to the combination of levels 4 and 5 of exposure to violence, since no respondent had level 5 exposure.

\section{Multivariate analysis}

Adjusted logistic regression analysis of the association between community violence and asthma showed that "knowing someone that had been beaten or injured with a firearm or knife" was the type of violence most strongly associated with the occurrence of asthma symptoms (OR $=1.41$; 95\%CI: 1.03-1.93). Likewise, asthma was $39 \%$ more common in children whose parents/guardians were aware of "gang war or drug traffic in the neighborhood" when compared to those whose parents did not report this kind of experience. Meanwhile, the other items - "direct victim of assault", "knowing someone that had been assaulted", and "knowing someone that had been murdered" -, when analyzed separately, did not show a statistically significant association with asthma symptoms (Table 2).
The study also showed a statistically significant association between asthma and levels of exposure to community violence, with $\mathrm{OR}=1.78$ (95\%CI: 1.11-2.85) for moderate exposure, $\mathrm{OR}=1.56$ (95\%CI: 1.12-2.18) for high exposure, and $\mathrm{OR}=1.94$ (95\%CI: 1.12-3.36) for maximum exposure (Table 3). However, in the estimates, the confidence intervals virtually overlapped, making it impossible to confirm a difference between the estimates for each measured level of violence.

\section{Discussion}

The current study found an association between community violence and asthma symptoms. Children whose parents or guardians were exposed to the highest level of violence showed nearly a twofold probability of manifesting such symptoms as compared to those whose parents were unexposed $\left(\mathrm{OR}_{\text {adjusted }}\right.$ 1.94; 95\%CI: 1.123.36). Prevalence of asthma symptoms was considerably higher among children whose parents reported awareness of gang warfare or drug traffic in the neighborhood and also among those who knew someone that had either been beaten or injured with a firearm or knife, with nearly $40 \%$ higher prevalence (OR: 1.39; 95\%CI: 1.01-1.92; OR: 1.41; 95\%CI: 1.03-1.93, respectively).

Various studies in the last decade, the majority of which in the United States, identified an association between community violence and asthma 8,9,10,11,12,20. Although the studies analyzed different outcomes, like hospitalizations and occurrence and number of days with symptoms, besides distinct contexts, they showed a similar association to that found in our study. Importantly, exposure to community violence could affect the parents' behavior, keeping their children longer at home, resulting in higher exposure to indoor allergens 10,12 . In addition, communities with heavier exposure to violence have limited access to health services, thus contributing to the severity of the asthma symptoms 12 . The literature further suggests that stress acts as a mediator between community violence and asthma symptoms $17,18,19$, but the fact that this variable was not the object of the current study highlights the importance of conducting longitudinal studies on the more precise relationship between these phenomena.

We also highlight that certain factors potentially associated with community violence and asthma, like domestic violence, parental/caregiver stress, and other child health indicators were not analyzed in the current study, which could explain the observed association by the presence of residual confounding. In addition, 
Characteristics of the study sample according to socio-demographic and community variables. Salvador, Bahia State, Brazil $(N=1,232)$.

\begin{tabular}{|c|c|c|}
\hline Variables & $\mathrm{n}$ & $\%$ \\
\hline \multicolumn{3}{|l|}{ Child } \\
\hline \multicolumn{3}{|l|}{ Gender } \\
\hline Male & 615 & 52.7 \\
\hline Female & 560 & 47.5 \\
\hline \multicolumn{3}{|l|}{ Age (years) } \\
\hline $4-5$ & 404 & 34.6 \\
\hline $6-7$ & 413 & 35.4 \\
\hline $8-11$ & 350 & 30.0 \\
\hline \multicolumn{3}{|l|}{ Asthma symptoms } \\
\hline No & 948 & 76.9 \\
\hline Yes & 284 & 23.1 \\
\hline \multicolumn{3}{|l|}{ Body mass index } \\
\hline Normal weight & 1,002 & 81.4 \\
\hline Underweight & 49 & 3.9 \\
\hline Overweight & 181 & 14.7 \\
\hline \multicolumn{3}{|l|}{ Family } \\
\hline \multicolumn{3}{|l|}{ Parents' history of asthma } \\
\hline Yes & 1,003 & 86.8 \\
\hline No & 155 & 13.2 \\
\hline \multicolumn{3}{|l|}{ Maternal schooling } \\
\hline Complete elementary or less & 266 & 23.0 \\
\hline From complete elementary to incomplete secondary & 557 & 48.1 \\
\hline Complete secondary or more & 334 & 28.9 \\
\hline \multicolumn{3}{|l|}{ Monthly income } \\
\hline$\leq \mathrm{R} \$ 300.00$ & 599 & 51.1 \\
\hline$\geq R \$ 300.01$ & 572 & 48.6 \\
\hline \multicolumn{3}{|l|}{ Paving } \\
\hline Streets, sidewalks, and byways unpaved & 439 & 35.6 \\
\hline Streets, sidewalks, and byways partially paved & 371 & 30.1 \\
\hline Streets, sidewalks, and byways paved & 422 & 34.3 \\
\hline \multicolumn{3}{|l|}{ Indoor walls } \\
\hline Plastered cinder blocks or bricks & 1,115 & 90.5 \\
\hline Non-plastered cinder blocks or bricks & 107 & 8.7 \\
\hline Scrap wood, tin, or cardboard or mud-and-wattle & 10 & 0.8 \\
\hline \multicolumn{3}{|l|}{ Community violence } \\
\hline Direct victim of assault & 219 & 17.8 \\
\hline Knows someone who was assaulted & 372 & 30.2 \\
\hline Knows someone beaten or wounded with firearm or knife & 292 & 23.7 \\
\hline Aware of gang wars or drug traffic in the neighborhood & 569 & 46.2 \\
\hline Knows someone who was murdered & 369 & 30.0 \\
\hline
\end{tabular}

the independent variable "community violence" was not measured directly with a specific instrument. The majority of the studies on the theme have found that exposure to a violent act such as being assaulted or witnessing a fight involving firearms or knives is already representative of the community violence phenomenon 8,9,10,11,12,20. When the SCAALA project was designed, there were no validated indicators for measuring this phenomenon in the Brazilian population, or for 


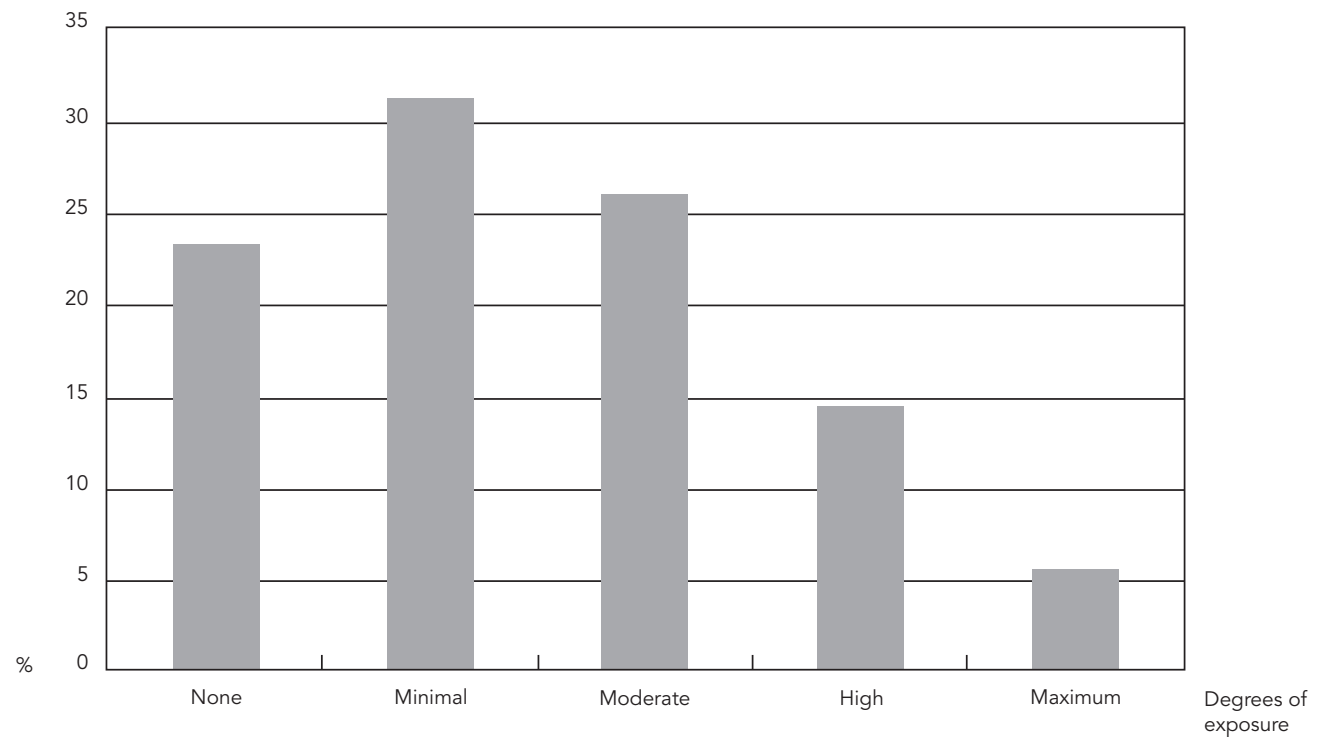

Table 2

Logistic regression between items on community violence and presence of asthma symptoms. Salvador, Bahia State, Brazil $(N=1,232)$.

\begin{tabular}{|c|c|c|c|c|}
\hline \multirow[t]{2}{*}{ Items on community violence } & \multicolumn{4}{|c|}{ Asthma symptoms } \\
\hline & $\mathrm{n}$ & Prevalence & Crude OR $(95 \% \mathrm{Cl})$ & Adjusted OR * $(95 \% \mathrm{Cl})$ \\
\hline Victim of assault & 84 & 21.8 & $1.05(0.74-1.48)$ & $1.20(0.82-1.74)$ \\
\hline Knows someone who was assaulted & 93 & 25 & $1.17(0.67-1.20)$ & $0.96(0.69-1.34)$ \\
\hline Knows someone who was beaten or wounded with firearm or knife & 82 & 28.1 & $1.43(1.06-1.92) * \star$ & $1.41(1.03-1.93) * \star$ \\
\hline Aware of gang war or drug traffic in the neighborhood & 150 & 26.4 & $1.41(1.08-1.84) \star \star$ & $1.39(1.01-1.92) \star \star$ \\
\hline Knows someone who was murdered & 93 & 25.2 & $1.18(0.89-1.58)$ & $1.17(0.93-1.48)$ \\
\hline
\end{tabular}

* Adjusted for child's sex and age, housing conditions, income, maternal schooling, parents' history of asthma, child's body mass index, and micro-areas; ** $p<0.05$.

constructing a variable based on items backed by the literature 10,20 .

Since the phenomenon involved the objective report of the respondent's experience with acts of violence, one assumes that the use of these items to evaluate the occurrence of community violence is appropriate. The consistency with associations found in North American studies 10,20 corroborates the strategy's plausibility.

The fact that the phenomenon of violence allows major variations in measurement hinders comparisons with other studies. Only two other studies used measures involving five levels, notwithstanding the differences in some items 10,20. Still, the mean exposure to community violence in our study ( $\mu=1.4$ ) was similar to that found in seven cities or boroughs studied in the United States, including Chicago $(\mu=1.3)$ and Manhat$\tan (\mu=1.4) 10$. Importantly, in the U.S. study, the target period for exposure to community violence was six months, thus differing from the one-year observation period in our study. 
Crude and adjusted association between intensity of exposure to community violence and occurrence of asthma symptoms. Salvador, Bahia State, Brazil $(\mathrm{N}=1,232)$.

\begin{tabular}{lcccc}
\hline $\begin{array}{l}\text { Exposure to community } \\
\text { violence }\end{array}$ & $\mathbf{n}$ & Prevalence & $\begin{array}{c}\text { Asthma symptoms } \\
\text { Crude OR (95\%Cl) }\end{array}$ & Adjusted OR * $(95 \% \mathrm{Cl})$ \\
\hline None & 47 & 16.4 & 1.00 & 1.00 \\
Minimal & 87 & 22.7 & $1.49(1.01-2.22)^{\star *}$ & $1.46(0.93-2.30)$ \\
Moderate & 86 & 27 & $1.88(1.26-2.81)^{\star *}$ & $1.78(1.11-2.85)^{\star *}$ \\
High & 45 & 25.3 & $1.72(1.08-2.73)^{\star *}$ & $1.56(1.12-2.18)^{\star *}$ \\
Maximum & 19 & 28.4 & $2.01(1.09-3.73)^{\star *}$ & $1.94(1.12-3.36)^{\star *}$ \\
\hline
\end{tabular}

* Adjusted for child's sex and age, housing conditions, income, maternal schooling, parents' history of asthma, child's body mass index, and micro-areas;

** $p<0.05$.

Concerning characterization of community violence in the sample, the questions with the highest rates concerned the existence of gang war or drug traffic in the neighborhood (46.2\%) and knowing someone who had been assaulted $(30.2 \%)$. In other words, nearly half of the interviewees lived in neighborhoods with frequent gang fights or drug traffic. A study in Belo Horizonte showed that violence was concentrated in slums dominated by gangs and the drug traffic 24 . Our findings point even more clearly to the association between community violence and the drug traffic in Brazil, with the resulting gang warfare. This form of violence appears to be more characteristic of Brazil, as compared to the North American study reporting only 15\% exposure to gang fighting 10 , and it is equally relevant to future studies expanding on the association between community violence and asthma.

\section{Conclusions}

The current study focused on the relationship between childhood asthma symptoms and acts of community violence on the periphery of Salvador. The study takes a pioneering approach to community violence in a Latin American city, where the issue is relevant. The existence of gang warfare or drug trafficking, as well as beatings and injuries with firearms and knives are among the factors potentially associated with health problems in children.

Our findings suggest the importance of violence as one of the factors in the process of multiple determination of asthma, and further studies are essential for exploring the limitations identified here and for verifying how such an association behaves. Broader interdisciplinary models may be useful for increasing the understanding of risk factors associated with this complex multifactorial disease. 


\section{Resumo}

O objetivo deste artigo foi identificar o grau de violência comunitária relatado por cuidadores de crianças entre quatro e 12 anos, além da influência dessa exposição na ocorrência de sintomas de asma nas crianças. Realizou-se um estudo transversal com 1.232 cuidadores residentes na cidade de Salvador, Bahia, Brasil. Investigaram-se sintomas de asma nas crianças e atos violentos na comunidade. Aproximadamente $75 \%$ dos cuidadores foram vítimas de violência comunitária no último ano, com $20 \%$ convivendo com graus elevados deste fenômeno. Encontrou-se prevalência de 28,4\% de sintomas asmáticos entre crianças expostas ao grau máximo de violência, e 16,4\% entre as não expostas. Encontrou-se associação estatisticamente significante entre exposição ao nível máximo de violência e ocorrência de sintomas asmáticos (OR ajustada $=1,94$; IC95\%: 1,12-3,36). Nossos achados sugerem a importância da violência comunitária como um dos fatores de risco associados com asma, sendo fundamental o desenvolvimento de novas pesquisas para esclarecer as limitações do presente estudo.

Violência; Asma; Criança

\section{Contributors}

G. C. Alves contributed with the literature review, data analysis, and drafting of various versions of the article. D. N. Santos contributed with the definition of the research methods, elaboration of the theoretical model, and writing and revision of the article. C. A. Feitosa contributed with the analysis of the questionnaire on community violence and construction of the variables, data analysis and interpretation, and writing and revision of the article. M. L. Barreto contributed with the elaboration of the study design, data interpretation, and reading and editing of the manuscript.

\section{References}

1. Chatkin M, Menezes AMB, Albernaz E, Victora CG, Barros FC. Fatores de risco para consultas em pronto-socorro por crianças asmáticas no Sul do Brasil. Rev Saúde Pública 2000; 34:491-8.

2. Barreto ML, Cunha SS, Alcântara-Neves N, Carvalho LP, Cruz AA, Stein RT, et al. Risk factors and immunological pathways for asthma and other allergic diseases in children: background and methodology of a longitudinal study in a large urban center in Northeastern Brazil (Salvador-SCAALA study). BMC Pulm Med 2006; 6:15.

3. Cooper PJ, Rodrigues LC, Cruz AA, Barreto ML. Asthma in Latin America: a public health challenge and research opportunity. Allergy 2008; 64:5-17.
4. Solé D, Wandalsen GF, Camelo-Nunes IC, Naspitz CK; ISAAC-Grupo Brasileiro. Prevalence of symptoms of asthma, rhinitis, and atopic eczema among Brazilian children and adolescents identified by the International Study of Asthma and Allergies in Childhood (ISAAC) - Phase 3. J Pediatr 2006; 82:341-6.

5. Worldwide variation in prevalence of symptoms of asthma, allergic rhinoconjunctivitis, and atopic eczema: ISAAC. The International Study of Asthma and Allergies in Childhood (ISAAC) Steering Committee. Lancet 1998; 351:1225-32. 
6. Moncayo AL, Vaca M, Oviedo G, Erazo S, Quinzo I, Fiaccone RL, et al. Risk factors for atopic and nonatopic asthma in a rural area of Ecuador. Thorax 2010; 65:409-16.

7. Barreto-do-Carmo MB, Santos DN, Amorim LDAF, Fiaccone RL, Cunha SS, Rodrigues LC, et al. Minor psychiatric disorders in mothers and asthma in children. Soc Psychiatry Psychiatric Epidemiology 2009; 44:416-20.

8. Jeffrey J, Sternfeld I, Tager I. The association between childhood asthma and community violence, Los Angeles County. Public Health Rep 2006; 121:720-8.

9. Wright RJ, Steinbach S.F. Violence: an unrecognized environmental exposure that may contribute to greater asthma morbidity in high risk innercity populations. Environ Health Perspect 2001; 109:1085-9.

10. Wright RJ, Mitchell H, Visness CM, Cohen S, Stout J, Evans R, et al. Community violence and asthma morbidity: the inner-city asthma study. Am J Public Health 2004; 94:625-32.

11. Swahn MH, Bossarte RM. The associations between victimization, feeling unsafe, and asthma episodes among high-school students. Am J Public Health 2006; 96:802-4.

12. Walker J, Land CL, Kub J, Tsoukleris M, Butz A. The effect of violence on asthma: are our children facing a double-edged sword? J Community Health 2008; 33:384-8.

13. Organización Mundial de la Salud. Informe mundial sobre la violencia y la salud: resumen. Washington DC: Organización Panamericana de la Salud/Organización Mundial de la Salud; 2002.

14. Assis SG, Avanci JQ, Pesce RP, Ximenes LF. Situação de crianças e adolescentes brasileiros em relação à saúde mental e à violência. Ciênc Saúde Coletiva 2009; 14:349-61.

15. Minayo MCS, Souza ER. Violence for all. Cad Saúde Pública 1993; 9:65-78.
16. Conselho Nacional de Secretários de Saúde. Violência: uma epidemia silenciosa. Brasília: Conselho Nacional de Secretários de Saúde; 2008.

17. Priftis KN, Chrousos GP. Neuroimmunomodulation in asthma: focus of the hypothalamic-pituitary-adrenal axys. Neuroimmunomodulation 2009; 16:263-4.

18. Priftis KN, Papadimitriou A, Nicolaidou P, Chrousos GP. Dyresgulation of the stress response in asthmatic children. Allergy 2008; 64:18-31.

19. Rattanjeet SV, Forsythe P, Vliagoftis H. The role of stress in asthma. Insight from studies on the effect of acute and chronic stressors in models of airway inflammation. Ann NY Acad Sci 2006; 1008:65-77.

20. Berz JB, Carter AS, Wagmiller RL, Horwitz SM, Murdock KK, Briggs-Gowan M. Prevalence and correlates of early onset asthma and wheezing in a healthy birth cohort of 2-to-3-year-olds. J Pediatr Psychol 2007; 32:154-66.

21. Sandberg S, Järvenpää S, Penttinen A, Paton JY, McCann DC. Asthma exacerbations in children immediately following stressful life events: a Cox's hierarchical regression. Thorax 2004; 59:1046-51.

22. de Meer G, Reijneveld SA, Brunekreef B. Wheeze in children: the impact of parental education on atopic and non-atopic symptoms. Pediatr Allergy Immunol 2010; 21:823-30.

23. Matos SMA, Jesus SR, Saldiva SRDM, Prado MS D'Innocenzo S, Assis AMO, et al. Overweight, asthma symptoms, atopy and pulmonary function in children of 4-12 years of age: findings from the SCAALA cohort in Salvador, Bahia, Brazil. Public Health Nutr 2011; [Epub ahead of print].

24. Beato Filho CC, Assunção RM, Da Silva BFA, Marinho FC, Reis IA, Almeida MCM. Conglomerados de homicídios e o tráfico de drogas em Belo Horizonte, Minas Gerais, Brasil, de 1995 a 1999. Cad Saúde Pública 2001; 17:1163-71.

Received on $07 /$ Nov/2010

Final version resubmitted on $27 / \mathrm{Jul} / 2011$ Approved on 13/Sep/2011 